\title{
Inflation and the Redistribution of Nominal Wealth
}

\author{
Matthias Doepke \\ University of California, Los Angeles, Centre for Economic Policy Research, and National Bureau \\ of Economic Research
}

\section{Martin Schneider}

Federal Reserve Bank of Minneapolis and New York University

\begin{abstract}
This study quantitatively assesses the effects of inflation through changes in the value of nominal assets. It documents nominal asset positions in the United States across sectors and groups of households and estimates the wealth redistribution caused by a moderate inflation episode. The main losers from inflation are rich, old households, the major bondholders in the economy. The main winners are young, middle-class households with fixed-rate mortgage debt. Besides transferring resources from the old to the young, inflation is a boon for the government and a tax on foreigners. Lately, the amount of U.S. nominal assets held by foreigners has grown dramatically, increasing the potential for a large inflation-induced wealth transfer from foreigners to domestic households.
\end{abstract}

For helpful comments we thank Stefania Albanesi, Orazio Attanasio, Harold Cole, Mark Gertler, Dror Goldberg, Burhanettin Kuruscu, Ellen McGrattan, Lee Ohanian, Monika Piazzesi, José-Víctor Ríos-Rull, Thomas Sargent, Nancy Stokey, Harald Uhlig, Gianluca Violante, Warren Weber, Randall Wright, the three anonymous referees, and seminar participants at various universities and conferences. David Lagakos and Juan Pablo Medina provided excellent research assistance. Financial support by the National Science Foundation (grant SES-0519265) and the Alfred P. Sloan Foundation is gratefully acknowledged. The views expressed herein are those of the authors and not necessarily those of the Federal Reserve Bank of Minneapolis or the Federal Reserve System.

[ Journal of Political Economy, 2006, vol. 114, no. 6]

(c) 2006 by The University of Chicago. All rights reserved. 0022-3808/2006/11406-0003 $\$ 10.00$ 


\section{Introduction}

An immediate consequence of an unanticipated change in the price level is wealth redistribution: inflation lowers the real value of nominal assets and liabilities and thereby redistributes wealth from lenders to borrowers. We quantitatively study the redistributional effects of inflation in the U.S. economy. More specifically, we ask, what would happen to the distribution of wealth among various types of economic agents if the United States were to enter a moderate inflation episode like that of the 1970s? We emphasize the role of money as a unit of account for assets and liabilities: inflation affects all nominal asset positions, not just cash positions. As a result, we find that even moderate inflation leads to substantial wealth redistribution.

We arrive at this conclusion in two steps. First, we document postwar nominal asset and liability positions in the U.S. economy for various groups of households as well as the government and foreign sectors. Then, we perform a simple thought experiment. Suppose that, for 10 years after a given benchmark year, inflation is five percentage points per year higher than expected at the end of the benchmark year. Our question is, if the real effects of inflation were due exclusively to the revaluation of nominal wealth, who would gain and who would lose? We provide an answer by revaluing nominal positions under various assumptions on agents' expectations of-and adjustments to-inflation during the episode.

To determine nominal positions, we combine data from the Flow of Funds Accounts (FFA) of the United States and the Survey of Consumer Finances (SCF), both published by the Federal Reserve Board. We consider not only directly held nominal assets and liabilities but also indirect nominal positions, which are due to shares in investment intermediaries and claims on the ownership of firms. For most securities, the data consist of book values that are hard to interpret and compare. We therefore construct the stream of future nominal payments associated with every major class of security and then restate all positions at market value. With this approach, we can also estimate the duration of agents' positions (or their maturity length), which allows us to gauge the effects of partially anticipated inflation.

We document several stylized facts that are critical for understanding the redistributional effects of inflation. At the sectoral level, we consider the evolution of U.S. nominal positions over the postwar period. We show that the early 1980s were a watershed. Before 1980, the major net nominal lender in the U.S. economy was the household sector. The postwar reduction of government debt was offset by increases in debt of the business sector, so that the size of total household nominal assets as a percentage of U.S. gross domestic product (GDP) remained rather 
stable. In the 1980s, however, government and mortgage debt began to grow quickly, relative to GDP, and the rest of the world became a major net nominal lender. After a brief slowdown in the 1990s, all these trends continued in the new millennium. In the early 2000s, mortgage debt moved to a historic high relative to GDP, and foreigners held more U.S. nominal assets than domestic households did.

Within the household sector, we document other changes. We consider the nominal wealth positions of U.S. households by age, by level of net worth, and by type of instrument held. On average, at any time, young middle-class households with mortgage debt are the major net nominal borrowers, and elderly households are net nominal lenders. Nominal asset holdings are highly concentrated, so that surprise inflation is largely a tax on the elderly rich. Comparing the 1989 and 2001 SCFs, we find that during the 1990s, the young poor caught up with the middle class in terms of debt positions. The dramatic fall in the household sector's net nominal position during the 1990s is due to both higher nominal debt of the young and lower nominal savings of the old.

Our inflation experiments are calibrated to capture different scenarios for how agents adjust expectations and portfolios during an inflation episode. This leads us to interval estimates for gains and losses of different sectors and groups of agents. For the benchmark year 1989, in the 5 percent inflation experiment, a coalition of rich and old households loses, in present-value terms, between 5.7 and 15.2 percent of GDP. About two-thirds of this loss accrues to households in the top 10 percent of the wealth distribution. On the winners' side, about 75 percent of the total gains in the household sector benefit middle-class households under the age of 45 , which receive a gift worth up to 45 percent of mean cohort net worth. The government also benefits through a reduction in the real value of its debt, with gains between 5.2 and 13.0 percent of GDP.

Throughout, we emphasize that redistributional effects depend on how quickly agents adjust to inflation. Our experiments distinguish surprise inflation episodes, in which the duration of positions is irrelevant, from gradual inflation episodes, in which gains and losses are relatively larger on positions of longer duration. The redistributional effects of gradual episodes thus depend not only on the size of nominal positions but also on the maturity structure of assets and liabilities. Our main result here is that gradual inflation episodes hurt foreigners and rich domestic households more than other groups. Foreigners and the rich hold more long-term bonds than poor and middle-class households, which hold most of their nominal assets as short-term deposits.

We also show how the increasing importance of asset markets relative to financial intermediaries has recently changed the potential effects of 
inflation on U.S. households. A key innovation of the late 1970s was the introduction of mortgage-backed securities. The big boom in mortgage lending that began in the early 1980s was not financed by an increase in deposits, but rather by long-term bonds bought by households (often indirectly through pension funds) as well as by foreigners. Together with the increased issue of long-term government debt, this securitization led to an increase in the duration of nominal positions of both foreigners and domestic households. At the same time, securitization reduced the maturity mismatch in the financial system and, hence, shifted the risk of gradual inflation from financial system shareholders to bondholders.

The implications of these changes over time can be gauged by comparing our results for the benchmark year 1989 to outcomes based on data from 2001. We find that for a surprise inflation episode, the losses of elderly domestic households are reduced by half. For a gradual inflation episode, the reduction is smaller-about one-third-because the portfolio shift toward longer-term assets makes households more vulnerable to gradual inflation and thus partly offsets the effect of smaller overall nominal positions. Under either scenario, however, in the year 2001, foreigners are particularly hard-hit by inflation, with losses between 4.8 and 7.7 percent of GDP.

Our work relates to an earlier literature that empirically assesses the wealth redistributional effects of high inflation in the 1970s in a number of countries (see Bach and Stephenson 1974; Cukierman, Lennan, and Papadia 1985). This early literature, however, lacks the main features of our analysis-the integration of sectoral and household data, the inclusion of indirect nominal positions, and market value adjustments. A more recent literature has focused on the economic implications of the revaluation of nominal government debt through inflation surprises. Bohn (1988) shows how debt revaluation can be used to insure the government against real shocks to its budget when markets are incomplete. ${ }^{1}$ Persson, Persson, and Svensson (1998) perform a thought experiment similar in spirit to ours in order to estimate the effect of inflation on government finances in Sweden. They find sizable effects of moderate inflation but attribute most of them to incomplete indexation of the tax and transfer system, as opposed to the direct devaluation of government debt. Burnside, Eichenbaum, and Rebelo (2006) examine the fiscal implications of currency crises in three middle-income countries. They find that devaluation of the dollar value of government debt is a more important source of depreciation-related government

\footnotetext{
${ }^{1}$ See also Bohn (1990b) and Sims (2001) for empirical evidence of this mechanism, and Bohn (1990a) on an open-economy extension.
} 
revenue than seigniorage, which is the source emphasized by most standard currency crisis models.

A connection between inflation and the wealth distribution can also arise through asymmetric incidence of the inflation tax. Erosa and Ventura (2002) and Albanesi (forthcoming) consider the link between inflation and inequality in model economies in which poor households hold more cash relative to other financial assets than rich households do. The key difference between the inflation tax literature and our work here is that the former deals with the effect of anticipated inflation on cash holdings. In contrast, we are concerned with unanticipated shocks on all nominal asset holdings, of which cash holdings are only a small part.

In Section II, we document the distribution of nominal assets and liabilities in the U.S. economy. In Section III, we quantify the effect of an inflation shock. In Section IV, we summarize our work here and consider where it might lead.

\section{Nominal Assets and Liabilities in the U.S. Economy}

Our methods for constructing nominal asset and liability positions in the U.S. economy are described in detail in the online Technical Appendix. Here we describe the organizing framework, summarize the main steps of the calculations, and present the results. By nominal assets and liabilities, we mean those denominated in U.S. dollars. We define the net nominal position (NNP) of an agent (e.g., a sector or an individual household) as the market value of all nominal assets minus the market value of all nominal liabilities. This definition includes the indirect nominal position, which is due to claims on investment intermediaries and the ownership of firms.

\section{A. Nominal Positions and Valuation}

Ultimately, every nominal claim in the economy is owned by households, nonprofit organizations, foreigners, or the government. Some of this ownership is indirect, however, through ownership claims on businesses. It is convenient to treat investment intermediaries separately from other businesses. Here an investment intermediary is defined as a financial intermediary that issues only one type of claim, namely, shares of itself. Examples are mutual funds and defined-contribution pension funds.

Indirect positions through ownership of investment intermediary shares can be calculated by assigning a portion, or fraction, of the intermediary's portfolio to the shareholder. We define the direct nominal position (DNP) as the sum of directly held nominal assets plus nominal assets held through investment intermediaries less nominal liabilities. 
If all firms in the economy held only real assets (such as physical and intangible capital) and had no nominal debt, then an agent's DNP would be the agent's true NNP.

We refer to ownership claims on businesses other than investment intermediaries as equity. Since the typical business both holds nominal assets and issues nominal debt, we need to make an assumption about how the value of equity depends on inflation. We follow Hall (2001) and McGrattan and Prescott (2005) in adopting a frictionless approach to the valuation of the aggregate business sector. Let net equity denote the market value of all equity claims on U.S. businesses not held by other U.S. businesses. We assume that it is equal to the value of real assets held by firms plus firms' DNP at market value (which is negative if firms are net debtors):

$$
\begin{aligned}
\text { net equity }= & \text { real assets of business sector } \\
& + \text { DNP of business sector. }
\end{aligned}
$$

We define the net nominal leverage ratio $\lambda$ as the nominal debt position of the business sector per dollar of equity held:

$$
\lambda=-\frac{\text { DNP of business sector }}{\text { net equity }} .
$$

This ratio is similar to a debt/equity ratio. It differs from conventional measures because it includes only nominal claims and because debt is net of all nominal assets held by the business sector.

The total NNP can now be computed by adding the indirect position to the direct position:

$$
\mathrm{NNP}=\mathrm{DNP}-\lambda(\text { equity held }) .
$$

This number summarizes an agent's exposure to purely nominal events in a world in which the only real effects of the events are due to the use of money as a unit of account for assets and liabilities.

Throughout this section, we consider only claims to future nominal payoffs that are fixed by contract between a borrower and a lender. We do not include positions that arise because of future nominal tax obligations. The reason is that future tax rates are uncertain and are themselves likely to change as a result of an inflation episode. Indeed, any inflation episode entails revaluation of nominal government debt, so that fiscal policy must change to satisfy the government budget constraint. Statements about tax-induced positions are thus hard to make outside of a model that can consider complete scenarios for fiscal policy. We study one such model in Doepke and Schneider (2006b). There we show how the aggregate and welfare effects of inflation episodes depend 
on whether the government rebates its windfall gain through tax cuts or social security benefit changes.

\section{B. Data}

Our principal data source for U.S. sectoral positions is the FFA, which provides a detailed breakdown of assets and liabilities for the household, business, foreign, and government sectors, as well as for various types of financial intermediaries. We use quarterly FFA data from 1952:Q1 to 2004:Q4. For U.S. Treasury debt, we supplement the FFA data with more detailed data available in a U.S. Treasury database, available from the University of Chicago's Center for Research in Security Prices (CRSP). For household positions, we rely on the 1989 and 2001 editions of the SCF, which offers detailed information on income and wealth for a representative cross section of U.S. households.

We define sectors by aggregating FFA sectors and, in some cases, adjusting FFA definitions, as explained in the online Technical Appendix. Our government sector includes the U.S. Treasury, U.S. state and local governments, the Federal Reserve System, and U.S. governmentsponsored retirement funds. The foreign sector contains not only the FFA's "rest of the world" sector but also foreign-owned banks and funding corporations. Our household sector differs from the FFA's in that we do not include the current value of defined-benefit pension funds. We treat assets in these funds as assets of the plan sponsor-the government or the business sector-rather than of the plan beneficiary. The reason is that benefits of these plans are usually indexed in nominal terms, so that inflation risk is borne by the plan sponsor. As in the FFA, our household sector includes the positions of nonprofit organizations. Our business sector aggregates all businesses other than investment intermediaries. Equity is thus a diversified claim on the aggregate business sector. The FFA does distinguish between equity in corporate and noncorporate businesses, and our sectoral calculations use separate values of the leverage ratio $\lambda$ in the indirect position computations. We also distinguish financial and nonfinancial businesses when interpreting the results below.

For the most part, we use the same financial instrument categories as the FFA. For some instruments, we use additional data sources to supplement the FFA data. For example, we use the Life Insurers Fact Book (a periodical published by the American Council of Life Insurers, Washington, DC) to determine the size of life insurers' separate account that backs rate-dependent instruments such as variable annuities. We also use the U.S. Commerce Department's Survey of Current Business to obtain market value estimates of foreign direct investment in the United States. Moreover, we incorporate financial assets only where we can identify 
both borrower and lender. This is in contrast to the FFA, where the corporate sector is credited with significant "miscellaneous financial assets." That category includes accounting items such as goodwill that are not claims on a counterparty.

The SCF provides survey responses from about 4,500 households together with weights that produce U.S. aggregates. The sample design is particularly well suited for our purposes since the survey oversamples rich households, those that hold the most assets. We use 1989 as one benchmark year because it is the earliest year with relatively low inflation for which the SCF is available. In addition, we use the 2001 edition to gauge how financial positions changed during the 1990s.

For the benchmark years 1989 and 2001, we combine the SCF and FFA data to obtain one consistent data set in which every nominal asset position of a household or sector corresponds to an offsetting nominal debt position elsewhere in the economy. To combine the data, we must adjust some FFA aggregates to reconcile them with the SCF's. We estimate indirect positions at the household level with the help of nominal leverage ratios derived from the FFA. We also use supplementary FFA tables to infer indirect positions that SCF households hold in individual retirement accounts (IRAs).

\section{Payment Streams and Market Value}

For most securities, positions in the FFA and SCF are stated at par value. The par values are not economically meaningful and are not comparable across securities of different maturities. We thus construct the payment streams that correspond to each asset.

For every major class of security and every year $t$, we are interested in the value of the sequence of future dollar payments $\left\{\nu_{t, s}^{j}\right\}_{s=1}^{\infty}$ that the typical owner of the security expects to get as of the end of year $t$, where $\nu_{t, s}^{j}$ is the expected payment on security $j$ in period $t+s$. We estimate payment streams by combining par value data from the FFA with data on maturities and coupon interest rates. We do this separately for several major types of instrument. For bonds, we distinguish among Treasury securities, municipal securities, corporate bonds, agency bonds, mortgage-backed securities, and many short-term securities. For any bond traded at $t$, the payment $\nu_{t, s}^{j}$ includes coupon and principal payments expected at $t+s$.

For loans, we distinguish mortgages from other loans, such as business and consumer credit. The payment $\nu_{t, s}^{j}$ on a loan outstanding at $t$ consists of amortization and interest payments due at $t+s$. Our estimation of those payments takes account of both repricing and prepayment. For example, when we construct payment streams on adjustable-rate mortgages (ARMs), we take into account the dependence of payments on 
changes in interest rates. For fixed-rate mortgages, we build in assumptions on refinancing, which is expected to occur when nominal interest rates fall.

Given the payment stream expected for an instrument as of year $t$, we calculate the market value of the instrument by discounting the payment stream with the nominal zero-coupon yield curve for $t$. Let $i_{t, s}$ denote the continuously compounded nominal yield to maturity in year $t$ on a zero-coupon bond that pays one dollar at $t+s$. The market value of the instrument as of year $t$ is then given by

$$
\sum_{s=1}^{\infty} \exp \left(-i_{t, s}\right) \nu_{t, s}^{i}
$$

We use this formula to derive market value adjustment factors that can be applied to all FFA and SCF positions, by year and instrument type. The resulting nominal positions at market value are discussed in the next two subsections.

\section{The Evolution of Nominal Positions by Sector}

Figure 1 summarizes the evolution of nominal positions by sector from 1952 to 2004. The black lines show the NNPs of the three ultimate claimants of nominal assets and liabilities: domestic households, the government, and the rest of the world. All positions are stated as a percentage of GDP. ${ }^{2}$ To illustrate the importance of indirect debt, grey lines show the DNPs of the household sector (solid line) and the rest of the world (dashed line). The indirect position of these sectors is given by the difference between the respective black and grey lines.

Figure 1 reveals drastic shifts in U.S. nominal positions since the 1980s. Until 1980, the position of the rest of the world was close to zero. The positive household position and the negative government position were mirror images, and both had been declining steadily for three decades. ${ }^{3}$ However, when net government debt began to grow in the 1980s, the rest of the world gradually became a major net lender. This new trend dramatically accelerated in 2001, a year that marked another turning point in net government debt.

The indirect position of U.S. households has been large and negative. Households' indirect debt (represented by the difference between the grey and black solid lines) has exceeded 25 percent of GDP for much of the last three decades and thus has significantly reduced households'

\footnotetext{
${ }^{2}$ Since the NNPs already contain indirect positions through claims on businesses, they sum to the discrepancy of the FFA.

${ }^{3}$ The ratio of the government's NNP to GDP is not identical to a standard debt/GDP ratio because the NNP nets out all direct and indirect holdings of nominal assets.
} 


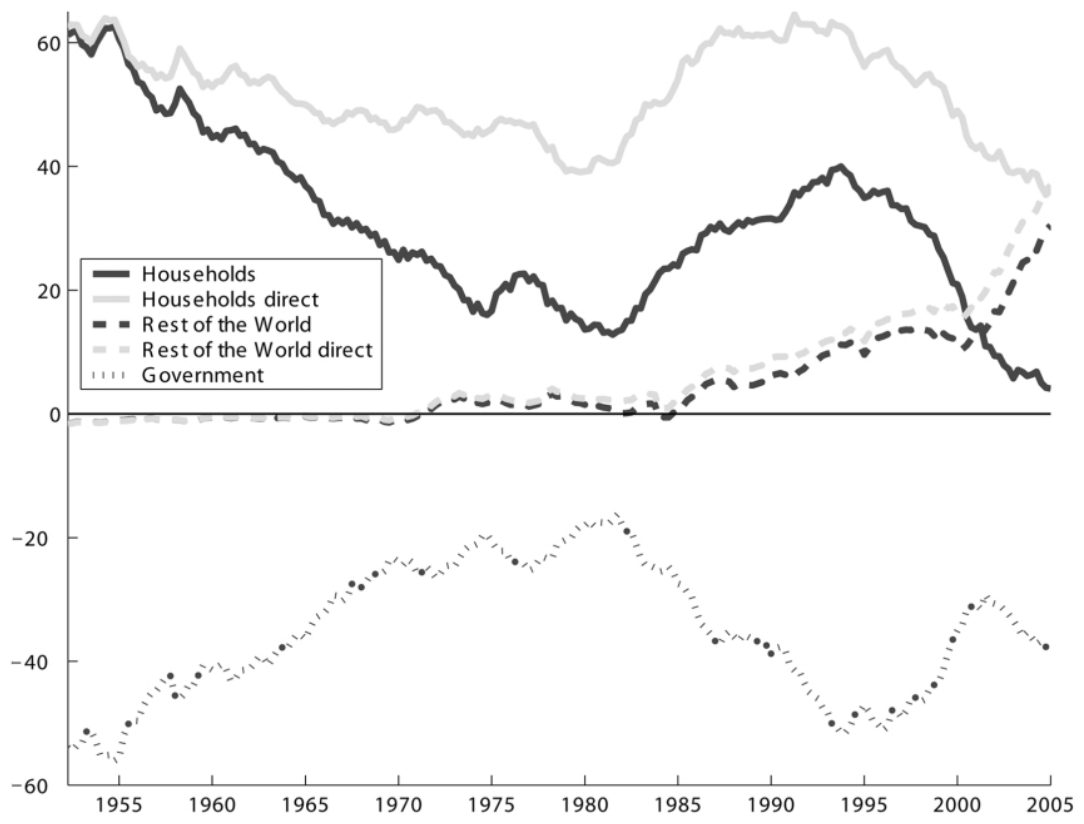

FIG. 1.-NNPs in the United States by sector from 1952 to 2004, as a percentage of GDP. Black lines: total NNP for households (solid), government (dotted), and the rest of the world (dashed). Grey lines: DNP for households (solid) and the rest of the world (dashed).

NNP. In contrast, the NNP of the rest of the world mostly has reflected foreigners' direct holdings of dollar instruments. The recent buildup of these holdings has turned foreigners into more important net nominal lenders than U.S. households are. In 2004, even foreigners' direct nominal position has eclipsed that of households.

Figure 2 shows the breakdown of the sectoral positions across broad nominal instrument types. The item "short instruments and loans" (fig. $2 b$ ) collects short-term claims such as deposits and commercial paper with nonmortgage loans. Instruments of this type mostly have a maturity (or time to repricing) of less than one year. The panel on "bonds" (fig. $2 c$ ) aggregates debt with maturity longer than one year, including government, corporate, and mortgage-backed bonds. The scale is the same across all four panels of figure 2, so that the positions in the instrument panels $(b, c$, and $d$ ) sum to those in panel $a$ (the aggregate), which matches figure 1 . In every panel, the three black lines depict the NNPs of the three end user sectors: U.S. households, the government, and the rest of the world. The grey lines again indicate the DNPs of the household and foreign sectors.

Figure 2 shows that longer maturity claims have recently become more 

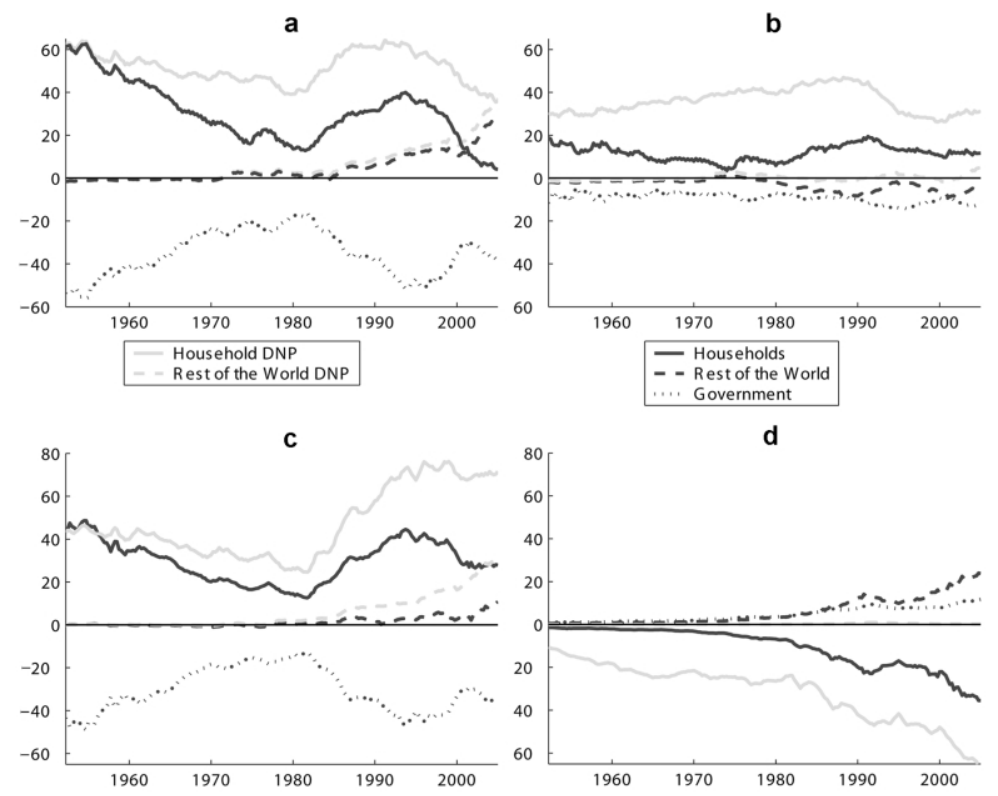

FIG. 2.-NNPs in the United States by sector and class of instrument, 1952-2004, as a percentage of GDP: $a$, total positions by sector (fig. 1); $b$, subtotals for short instruments with maturity up to one year; $c$, bonds with maturity above one year; $d$, mortgages. All panels are drawn to the same scale.

important for intersectoral borrowing and lending. In particular, trends of households' net mortgage and bond positions break around 1980, whereas the net short position increases relatively slowly until 1990 and declines thereafter. These shifts reflect two developments in the financial system. One is that households have been increasing their savings for retirement through pension plans and mutual funds, so their nominal holdings have become more tilted toward long-term bonds and away from deposits. The other important development is the increasing securitization of mortgages. The increase in mortgage lending over the last two decades has not been accompanied by an increase in deposits (as might have been expected had the traditional banking system of the 1950s still been in place), but rather by an increase in long-term bonds.

In our calculations, bonds backed by mortgages in federally related mortgage pools are treated as pass-through securities; that is, the bondholders are assumed to own the pool mortgages directly. However, to illustrate the financing of mortgage borrowing through bonds, one can alternatively think of a mortgage pool as an intermediary that issues bonds and holds mortgages. On the basis of this interpretation, the 
a

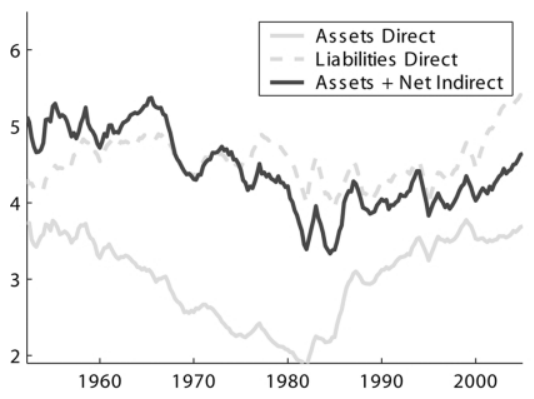

C

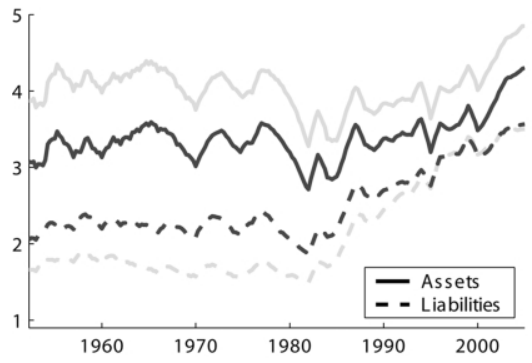

b

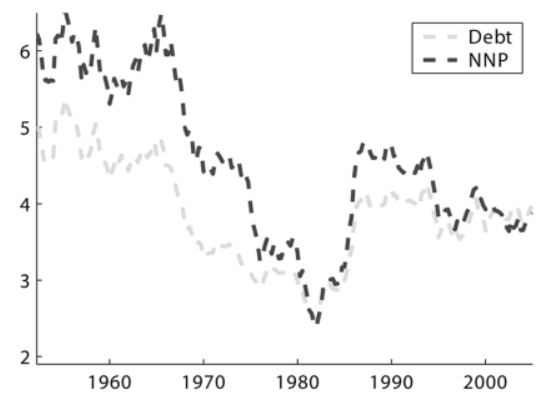

d

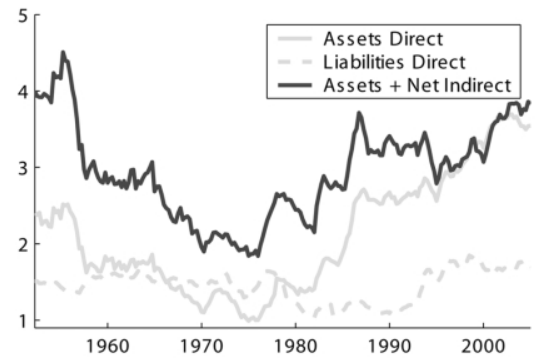

FIG. 3.-Duration (value-weighted average maturity in years) of nominal asset and liability positions in the United States by sector, 1952-2004: $a$, households; $b$, government; $c$, business sector (black) and financial system (grey); $d$, the rest of the world. Line styles indicate asset (solid) or liability positions (dashed). For households, government, and the rest of the world (panels $a, b$, and $d$ ), grey lines indicate the duration of direct assets and liabilities; black lines include also the net indirect position due to equity. For business (panel c), black and grey lines distinguish the total business and financial sectors, respectively.

lower panels of figure 2 report pool mortgages as bonds. Mortgagebacked bonds account for most of the recent surge in bond holdings by both the household and the foreign sectors. In addition, the negative indirect bond positions of these sectors (which arise through equity holdings) have substantially increased. For households, this increase is accompanied by a decrease in indirect short-term debt.

Figure 3 offers a closer look at the maturity of sectoral positions by reporting the duration (in terms of years) of assets and liabilities for the three end user sectors as well as the business sector and the financial system. The duration of a payment stream measures the value-weighted average maturity of the payments and therefore also the marginal change of the present value in response to a parallel shift in the yield 
curve, due to, for example, an increase in expected inflation. ${ }^{4}$ Comparing the durations of assets and liabilities shows that some sectors exhibit a systematic maturity mismatch. For example, the financial system (fig. 3c) always borrows short and lends long. So does the rest of the world (fig. 3d); at least it has since 1980, when its position became nonnegligible. Both of these sectors would thus be hurt by an anticipated permanent shift in inflation. In contrast, households' direct liabilities (fig. 3a) have a much longer duration than their direct holdings; the two durations become similar only when the indirect position due to equity is taken into account.

Up until the early 1980s, the duration of U.S government debt was gradually reduced. As a result, households (at the time, the major owners of government debt) saw a reduction in the duration of their nominal assets, as the rest of the world did. At the same time, there was little change in the duration of private credit positions: households' direct liabilities, as well as the assets and liabilities of the financial system and the corporate sector, stayed essentially flat. A substantial shortening of these positions came only with the advent of high and volatile inflation in the late 1970s. In the 1980s, duration increased again as inflation receded. However, rather than return to the maturity mismatches of the 1960 s, the financial system further narrowed the gap between the durations of its assets and liabilities. This is another key implication of securitization.

\section{E. The Cross Section of Household Nominal Positions}

The SCF data allow us to add detail to the household sector by distinguishing among various groups of households. We first sort households into six cohorts, by age of the household head: households aged 35 years and younger, 36-45, 46-55, 56-65, 66-75, and over 75. For each cohort, we refer to the top 10 percent of households as measured by net worth as rich households. The rest of the households are then sorted by income into two additional groups, labeled the middle class (70 percent of the population) and the poor (the bottom quintile of the income

\footnotetext{
${ }^{4}$ Formally, for a payment stream $\left\{d_{t}\right\}_{t=1}^{T}$, let $V(\Delta)$ denote the present value when the entire yield curve is shifted up by $\Delta$ :

$$
V(\Delta)=\sum_{t=1}^{T} \exp \left[-\left(i_{t}+\Delta\right) t\right] d_{t}
$$

Here duration is defined as the marginal percentage change in the value of the payment stream evaluated at the original yield curve:

$$
\frac{V^{\prime}(0)}{V(0)}=\sum_{t=1}^{T} t \frac{\exp \left(-i_{t} t\right) d_{t}}{\sum_{\tau=1}^{T} \exp \left(-i_{\tau} \tau\right) d_{\tau}} .
$$
}


TABLE 1

Net Nominal Positions of U.S. Households in 1989

\begin{tabular}{|c|c|c|c|c|c|c|}
\hline \multirow{2}{*}{$\begin{array}{l}\text { TYPE OF } \\
\text { INSTRUMENT }\end{array}$} & \multicolumn{6}{|c|}{ AgE CoHort } \\
\hline & $\leq 35$ & $36-45$ & $46-55$ & $56-65$ & $66-75$ & $>75$ \\
\hline & \multicolumn{6}{|c|}{ A. All Households } \\
\hline Short-term & -2.3 & 4.4 & 5.5 & 10.8 & 12.4 & 18.1 \\
\hline Bonds & 11.7 & 13.2 & 11.4 & 12.6 & 12.4 & 16.4 \\
\hline Mortgages & -47.5 & -23.4 & -10.5 & -4.7 & -1.4 & -.4 \\
\hline Equity & -4.5 & -4.3 & -4.1 & -3.5 & -4.0 & -3.5 \\
\hline \multirow[t]{2}{*}{ Total NNP } & -42.6 & -10.1 & 2.3 & 15.2 & 19.4 & 30.6 \\
\hline & \multicolumn{6}{|c|}{ B. Poor } \\
\hline Short-term & -35.9 & -10.3 & .5 & 8.9 & 17.7 & 25.0 \\
\hline Bonds & 15.3 & 5.4 & 3.0 & 3.7 & 5.8 & 2.0 \\
\hline Mortgages & -13.2 & -24.9 & -6.5 & -3.5 & -5.9 & -.1 \\
\hline Equity & -2.8 & -4.0 & -2.5 & -1.6 & -.1 & -.5 \\
\hline \multirow[t]{2}{*}{ Total NNP } & -36.6 & -33.8 & -5.5 & 7.5 & 17.5 & 26.4 \\
\hline & \multicolumn{6}{|c|}{ C. Middle Class } \\
\hline Short-term & -14.6 & 2.0 & 6.2 & 11.0 & 17.6 & 31.7 \\
\hline Bonds & 14.9 & 13.7 & 11.5 & 13.4 & 11.2 & 8.6 \\
\hline Mortgages & -112.6 & -45.4 & -20.8 & -8.7 & -2.3 & -.9 \\
\hline Equity & -1.7 & -1.9 & -1.7 & -1.7 & -1.3 & -1.3 \\
\hline \multirow[t]{2}{*}{ Total NNP } & -114.0 & -31.6 & -4.8 & 14.0 & 25.2 & 38.1 \\
\hline & \multicolumn{6}{|c|}{ D. Rich } \\
\hline Short-term & 3.6 & 6.5 & 5.2 & 10.8 & 9.7 & 11.8 \\
\hline Bonds & 10.3 & 13.4 & 11.6 & 12.5 & 13.2 & 20.5 \\
\hline Mortgages & -22.2 & -10.4 & -4.8 & -2.5 & -.8 & -.1 \\
\hline Equity & -5.7 & -5.7 & -5.4 & -4.5 & -5.4 & -4.7 \\
\hline Total NNP & -14.0 & 3.8 & 6.6 & 16.3 & 16.7 & 27.5 \\
\hline
\end{tabular}

each group as a percentage of average net worth in the group. In each group, components sum to total NNP.

distribution). ${ }^{5}$ Table 1 presents 1989 household NNPs by age and class, together with a decomposition by type of instrument. For every cohort, average cohort positions have been normalized by cohort net worth. The Technical Appendix contains further information on household balance sheets by group.

On average, young households borrow, and old households lend. While this basic pattern is true for all three classes, it is most pronounced for the middle class: young, middle-class households have the largest ratios of net debt to net worth, whereas old middle-class households have the largest ratios of net nominal savings to net worth. Among the rich, only the youngest cohort borrows, and only a modest percentage of net worth. The positive positions of the elderly rich are sizable, but

\footnotetext{
${ }^{5}$ The share of households that are simultaneously in the top 10 percent of the wealth distribution and in the bottom 20 percent of the income distribution is negligible in the SCF.
} 
smaller, as a percentage of net worth, than those of the elderly middle class. Among the poor, the young borrow somewhat more, and the old lend somewhat less than the respective cohort averages.

Borrowing by the young, middle-class households mostly takes the form of mortgage loans. In contrast, the young poor rely more on consumer credit, grouped under short-term instruments. Among the older net lender cohorts, the duration of nominal asset holdings differs substantially. Old, rich households keep a large part of their nominal savings in long-term bonds, whereas the old middle class and especially the old poor rely more on short-term instruments such as deposits. Another feature of the rich is that indirect debt due to equity holdings significantly reduces their NNPs at all ages.

\section{Inflation and Wealth Redistribution}

We now assess the redistribution of wealth that is induced by the surprise arrival of a moderate inflation episode in the U.S. economy. Suppose that, starting from the end of a given benchmark year, inflation over the next 10 years is five percentage points higher than initially expected. We estimate the present-value gain or loss from such an inflation episode for every sector and group of households we have discussed above. Of course, both the scale and the nature of redistribution depend on how quickly agents adapt to higher inflation. We do not take a stand on exactly how expectations are formed or portfolios adjusted. Instead, we construct two scenarios that provide upper and lower bounds on redistribution and use these bounds to illustrate the qualitative implications of adjusting expectations.

\section{A. Inflation Scenarios}

Under the upper-bound, or full surprise, scenario, we confront agents with a surprising one-time jump in the price level that leaves nominal interest rates unchanged. Redistribution occurs because a jump in the price level proportionally lowers the real value of all nominal payments. The size of the jump is set to the total change in the price level over the inflation episode. In contrast, the lower-bound, or indexing ASAP, scenario corresponds to a surprising one-time announcement that inflation will be five percentage points higher than expected for the next 10 years. Bond markets immediately incorporate the revised inflation expectations into the nominal yield curve. Redistribution occurs because future nominal payments are discounted at higher interest rates. The present-value gains and losses are smaller here than in the full surprise scenario because any given position is not affected by the change in the price level over the entire episode, but only by the change up to the 
maturity of the position itself. As we will see, the indexing ASAP scenario is equivalent to assuming that agents switch to inflation-indexed securities as soon as their nominal positions reach maturity, which accounts for the label.

To define the scenarios formally, let $i_{t}^{t+n}$ denote the total nominal yield on an $n$-year nominal zero-coupon bond at date $t$. Before any inflation surprise, the present value of one dollar at date $t+n$ is $v_{t}(n)=\exp \left(-i_{t}^{t+n}\right)$. Suppose that an inflation episode brings extra inflation of $\Delta$ per year for $T$ years, starting at $t$. Under the full surprise (FS) scenario, the nominal term structure remains unchanged, but the value of a dollar at date $t$ is reduced to $\exp (-\Delta T)$ by the jump in the price level. The new date $t$ present value of a dollar at $t+n$ is then

$$
v_{t}^{\mathrm{FS}}(n)=\exp \left(-i_{t}^{n}\right) \exp (-\Delta T)=v_{t}(n) \exp (-\Delta T) .
$$

Under the full surprise scenario, the percentage gain or loss on a position is thus independent of the maturity $n$ of that position.

Under the indexing ASAP (IA) scenario, the new inflation path is announced at the end of the benchmark year, and bond prices immediately adjust. Suppose that the Fisher equation holds ex ante, so that $i_{t}^{t+n}=r_{t}^{t+n}+\pi_{t}^{t+n}$, where $r_{t}^{n}$ is the total real yield and $\pi_{t}^{n}$ is cumulative expected inflation. Assume that the real yield curve remains unchanged after the announcement. Then the nominal $n$-year yield increases to $\tilde{i}_{t}^{t+n}=i_{t}^{t+n}+\Delta \min \{n, T\}$. Under the indexing ASAP scenario, the date $t$ present value of a dollar at $t+n$ becomes

$$
\begin{aligned}
v_{t}^{\mathrm{IA}}(n) & =\exp \left(-\tilde{i}_{t}^{t+n}\right) \\
& =\exp \left[-\left(i_{t}^{t+n}+\Delta \min \{n, T\}\right)\right] \\
& =v_{t}(n) \exp (-\Delta \min \{n, T\}) .
\end{aligned}
$$

Figure 4 illustrates how the real value of a payment of one dollar due at some future date is affected in the two inflation scenarios. In the full surprise scenario (the dashed lines in the figure), the loss is independent of the maturity of the payment, whereas under indexing ASAP, the remaining value declines in maturity. Both scenarios lead to the same percentage loss for payments due beyond $T$ (the length of the inflation episode). Moreover, the effect of maturity on the size of the loss under indexing ASAP becomes less pronounced as the inflation rate increases. For example, at 5 percent inflation per year over 10 years, a payment due in five years loses about 40 percent of its value under full surprise but only about 20 percent under indexing ASAP, or about half of the full surprise loss. At 25 percent inflation per year, in contrast, the losses on a payment due in five years are more similar, with a loss of 92 percent under full surprise versus 75 percent under indexing ASAP. In the ex- 


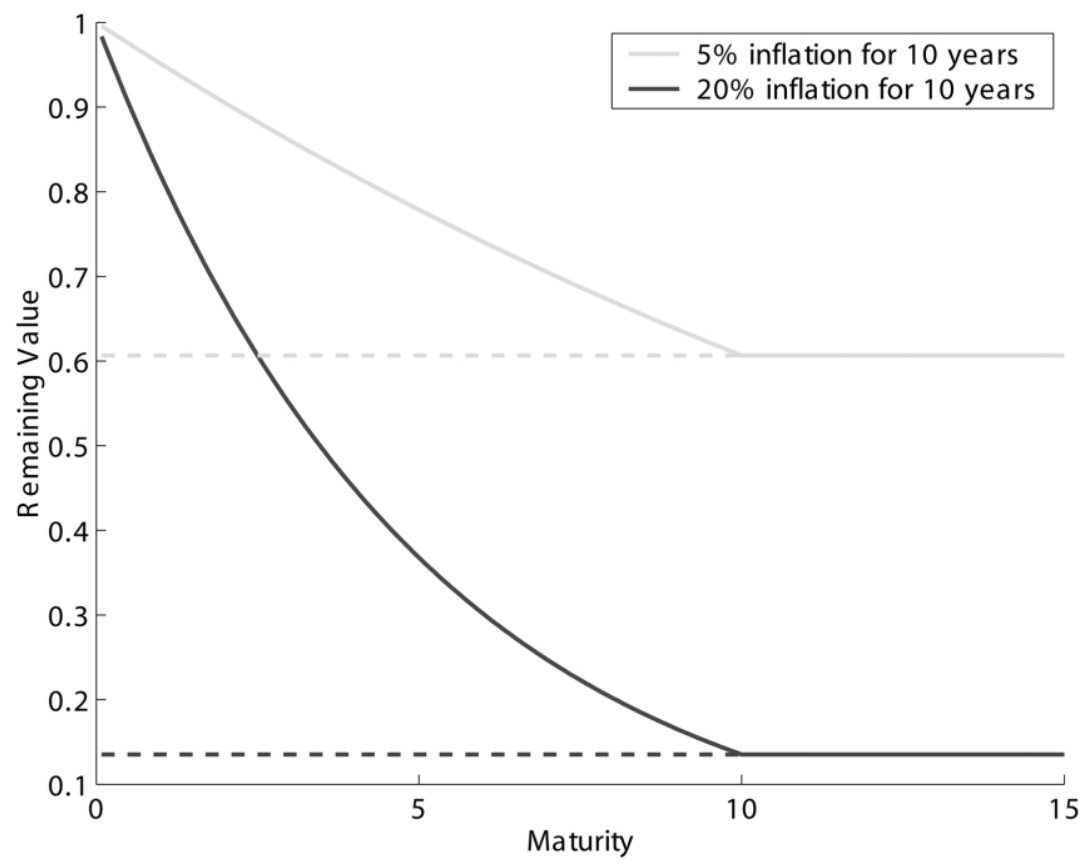

FIG. 4.-Remaining real value of one dollar due at different dates in the future after inflation experiments under indexing ASAP (solid lines) and full surprise (dashed lines) scenarios.

treme case of a hyperinflation, even payments due in a few months would be wiped out almost entirely, regardless of the expectations scenario.

The indexing ASAP scenario provides a lower bound on redistribution effects because agents are implicitly assumed to fully index their positions after the first surprise. To see this, consider the future value as of date $t+T$ of a dollar payment at $t+n$, that is, the payoff, at the end of the inflation episode, on an initial investment of maturity $n$ with a par value of one dollar. For $n<T$, the future value of a dollar payment is

$$
\exp \left(r_{t}^{t+T}\right) v_{t}^{\mathrm{IA}}(n)=\exp \left(-\pi_{t}^{t+n}-\Delta n\right) \exp \left(r_{t+n}^{t+T}\right)
$$

This payoff consists of two pieces: the real value of the position at date $t+n$ and the return on investment from $t+n$ to $t+T$. Under indexing ASAP, only the former is affected by inflation and reflects the loss incurred because of inflation up to $t+n$. Once the position comes due at $t+n$, the funds are reinvested at the real interest rate. In other words, 
the portfolio is indexed as soon as possible.$^{6}$ Full indexation is possible here because of the extreme assumption that bond markets perfectly foresee the entire inflation path. The indexing ASAP scenario thus not only provides a lower bound for our quantitative statements but also captures qualitative features of a gradual inflation episode, during which the path of inflation is partially anticipated.

In actual moderate inflation episodes, inflation often occurs in several surprising bursts, so that full indexation after the first surprise is less likely. The full surprise scenario goes to the other extreme: agents are effectively assumed to not adjust their positions at all during the inflation episode. Under this scenario, the future value at $t+T$ of a dollar payment at $t+n$ is

$$
\exp \left(r_{t}^{t+T}\right) v_{t}^{\mathrm{FS}}=\exp \left(-\pi_{t}^{t+n}-\Delta n\right) \exp \left[r_{t+n}^{t+T}-\Delta(T-n)\right] .
$$

Besides the inflation-induced loss on the position at $t+n$-which is the same as that in the indexing ASAP scenario-the full surprise scenario has additional losses of $\Delta$ per period between dates $t+n$ and $t+T$. In our description so far, these losses are attributable to a jump in the price level at $t$. An alternative interpretation is that, at all dates $t<T$, the extra inflation up to that point is perceived as a temporary anomaly, and things are expected to return to normal the following period. Expectations therefore never adjust, and portfolio positions as well as nominal interest rates remain unchanged. Thus the full surprise scenario not only provides an upper bound for our quantitative statements but also captures qualitative properties of surprise inflation episodes, during which inflation occurs as repeated surprises.

Since the period length in our valuation framework is a year for most instruments, the above discussion applies directly only to positions with maturity of one year or longer. We make analogous calculations for shorter claims. Under the indexing ASAP scenario, we assume that positions in deposits, nonmortgage loans, and short-term paper-all valued at par in our valuation exercise-can be adjusted within the first year of the inflation episode. The idea is that while repricing loans and withdrawing deposits typically take time, agents will try to earn a different interest rate as soon as possible. We devalue the par values by a six-month inflation surprise. Similarly, we devalue ARMs by a one-year inflation surprise. This captures the fact that, for most ARMs, adjustment can occur only at specific times. Under the full surprise scenario, in

\footnotetext{
${ }^{6}$ For the wealth effects we are interested in, exactly how agents achieve inflation protection for short positions does not matter. In practice, we could imagine reinvestment at a higher nominal interest rate or at the real interest rate or, alternatively, earlier consumption. Also irrelevant is how the loss on longer-term positions is realized. With perfect foresight after the initial announcement, the wealth effects are the same whether bonds are sold at a loss early or held to maturity.
} 


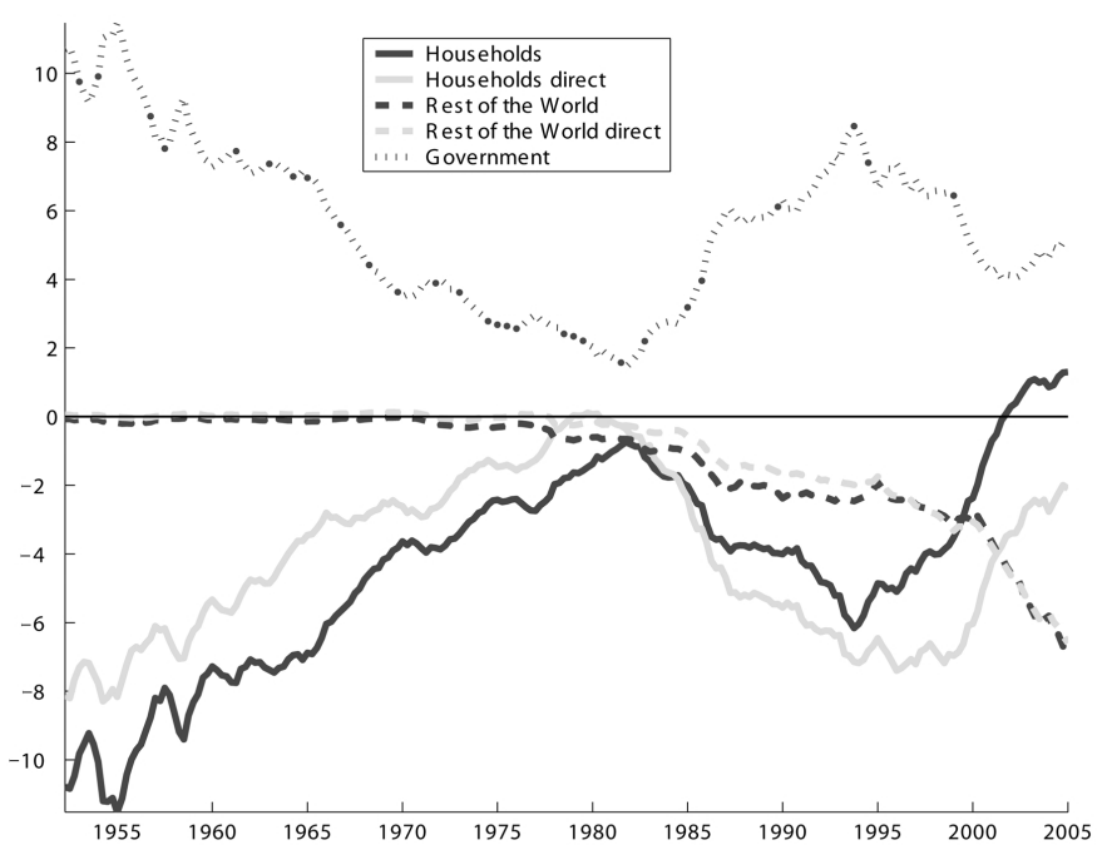

FIG. 5.-Wealth gains or losses by sector under the indexing ASAP scenario for benchmark years 1952-2004. Benchmark years are measured along the horizontal axis. Every experiment is a surprising announcement, at the end of a benchmark year, that inflation will be five percentage points per year higher than previously expected over the next 10 years. Gains and losses are in present-value terms, stated as percentages of benchmark year GDP.

which all positions are multiplied by the same surprise inflation factor, we also multiply deposit, nonmortgage loan, and ARM positions by that factor. $^{7}$

\section{B. Redistribution across Sectors}

Figure 5 plots redistribution over time under the indexing ASAP scenario for our baseline episode of 5 percent inflation per year for 10 years. Time on the horizontal axis indicates benchmark years for the start of the inflation episode, and the lines represent sectoral gains and losses as a percentage of GDP. For example, the black dotted line (representing the government) is equal to 8.5 percent for 1993:Q3. This means that if a baseline inflation episode had begun in 1993:Q3, the

${ }^{7}$ We assume indexing even on instruments for which current interest rates are zero, such as some checkable deposits. This is in line with the role of the indexing ASAP scenario as a lower bound. 
present-value gain to the government would have been at least 8.5 percent of GDP. Under the full surprise scenario, the value of all nominal positions drops by the same percentage-for the baseline episode, 39.4 percent-and the gains and losses can be read off directly from the positions in figure 1 , multiplied by -0.394 . For example, since the NNP of the government in 1993:Q3 was -51.6 percent of GDP, the presentvalue gain of the government from the baseline episode starting in 1993: Q3 would have been at most $-0.394(-51.6)=20.3$ percent of GDP.

Under either scenario, the government is the only winner among end user sectors; both domestic households and the rest of the world lose. Interval estimates for government gains are as low as 1.4-6.4 percent for 1981 and as high as 11.5-22.9 percent for 1954; the estimates for 2004:Q4 are 5.1-15.0 percent. Up to the 1980s, an inflation episode would have mostly amounted to a tax on the domestic household sector, with little effect on foreigners. More recently, inflation has become a powerful tool for implicitly defaulting on foreign debt; estimated rest of the world losses for 2004:Q4 are at a historical high of 6.9-12.0 percent of GDP. ${ }^{8}$ Foreigners' losses have recently increased under either scenario, and their share of the loss is particularly large in the indexing ASAP scenario. Indeed, since late 2001, U.S. households would have been net winners under indexing ASAP. This is true even though both households and the rest of the world are net lenders: what matters here is differences in the duration of sectoral positions. Figure 3 shows that foreigners lend long and borrow short, whereas the opposite is true for households. As a result, a gradual inflation episode, which hurts long positions more than short, would be beneficial for the domestic household sector and harmful for foreigners.

The behavior of indirect gains and losses reflects the importance of maturity mismatch in the business sector. Under the full surprise scenario, equity holders always gain. The gain follows the evolution of corporate debt: it increased gradually after World War II to a first peak of 11.7 percent in 1974 and has been hovering between 9 percent and 13 percent since the early 1970s. Surprise inflation is therefore good for equity holders. In contrast, gradual inflation episodes were historically bad for equity holders: before 1980, equity holders would have incurred losses on their indirect positions under the indexing ASAP

\footnotetext{
${ }^{8}$ These losses are expressed in real dollars. In principle, foreigners might care more about losing buying power in their own country than in the United States. If purchasing power parity holds, however, U.S. inflation will be accompanied by a proportional devaluation of the U.S. dollar, in which case the real losses of the foreigners will be the same from both perspectives. On the basis of a comprehensive measure of net foreign exposure (including equity and foreign direct investment [FDI] in addition to direct nominal positions), Gourinchas and Rey (2005) have recently argued that such exchange rate-driven revaluations of foreign asset positions account for a major part of external financial adjustment in the United States.
} 
TABLE 2

Wealth Redistribution across Sectors after 5 Percent Inflation Experiment

\begin{tabular}{|c|c|c|c|c|c|c|c|c|c|c|}
\hline \multirow[b]{3}{*}{ YEAR } & & & & & \multicolumn{6}{|c|}{ All Households } \\
\hline & \multicolumn{2}{|c|}{ Government } & \multicolumn{2}{|c|}{$\begin{array}{c}\text { REST OF } \\
\text { THE WORLD }\end{array}$} & \multicolumn{2}{|c|}{ Total } & \multicolumn{2}{|c|}{ Losses } & \multicolumn{2}{|c|}{ Gains } \\
\hline & FS & IA & FS & IA & FS & IA & FS & IA & FS & IA \\
\hline $\begin{array}{l}1989 \\
2001\end{array}$ & $\begin{array}{l}+13.0 \\
+10.8\end{array}$ & $\begin{array}{l}+5.2 \\
+3.6\end{array}$ & $\begin{array}{l}-5.2 \\
-7.7\end{array}$ & $\begin{array}{l}-3.2 \\
-4.8\end{array}$ & $\begin{array}{l}-7.3 \\
-1.2\end{array}$ & $\begin{array}{l}-2.2 \\
+1.1\end{array}$ & $\begin{array}{r}-15.2 \\
-8.2\end{array}$ & $\begin{array}{l}-5.7 \\
-3.6\end{array}$ & $\begin{array}{l}+7.9 \\
+7.0\end{array}$ & $\begin{array}{l}+3.5 \\
+4.7\end{array}$ \\
\hline
\end{tabular}

NOTE.-Gain or loss of each sector after a 5 percent inflation episode lasting 10 years as a percentage of U.S. GDP under two scenarios, full surprise (FS) and indexing ASAP (IA), and for two baseline years (start of the inflation episode), 1989 and 2001.

scenario because of maturity mismatch in the financial sector. In the traditional banking environment of the 1950s and 1960s, anticipated inflation would have implied losses on banks' fixed-rate mortgages and bond portfolios that could not be offset by gains on short liabilities. Since the corporate debt market was then relatively small, the losses of the financial system would have led to a loss on the shareholders' overall indirect position. After 1980, maturity mismatch was reduced through securitization (fig. 3). Losses on mortgages are now offset by gains on mortgage-backed securities as well as by the increased stock of corporate debt. As a result, since 1984, equity holders would have benefited from inflation under both scenarios.

Table 2 summarizes the inflation-induced redistribution of wealth across sectors while separating gains and losses among households, on the basis of SCF data for the benchmark years 1989 and 2001. The results provide a further illustration of the role that the duration of a position plays for redistribution. Given the devaluation factors displayed in figure 4, under the indexing ASAP scenario, large losses accrue only on positions with a relatively long duration. Accordingly, in 1989, under indexing ASAP, the largest loss is borne by the rest of the world, which has a position that is smaller than that of the household sector, but of a longer duration. In contrast, under the full surprise scenario, losses in this year are proportional to the overall position, so that the household sector loses the most.

The size of the inflation shock affects gains and losses under the full surprise and indexing ASAP scenarios in different ways. Under the full surprise scenario, all nominal assets and liabilities are devalued with the cumulative inflation over the entire episode, so that gains and losses are proportional to the size of the inflation shock. In contrast, under the indexing ASAP scenario, gains and losses also depend on the duration of a position. As discussed above, duration matters less for determining gains and losses as inflation rates increase, so that gains or losses under the indexing ASAP scenario increase more than propor- 


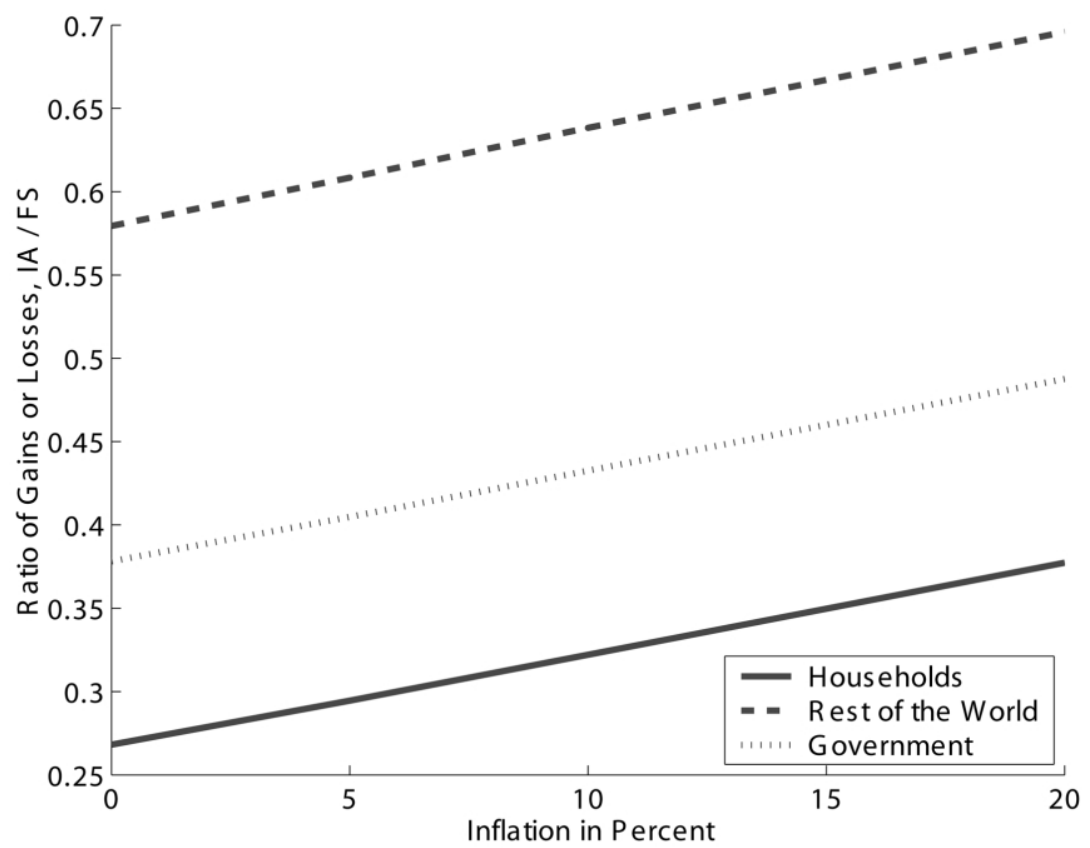

FIG. 6.-Ratio of net gain or loss under the indexing ASAP (IA) scenario to net gain or loss under the full surprise (FS) scenario for different inflation rates, based on a 10year inflation episode starting in benchmark year 1989 .

tionally with cumulative inflation. To illustrate this effect, figure 6 plots the ratio of the sectoral gain or loss under the indexing ASAP scenario to its counterpart under the full surprise scenario for different inflation rates, all based on the benchmark year 1989. For a given inflation experiment, this ratio is highest for the rest of the world, which reflects the long average duration of the nominal asset portfolio of this sector. For a given sector, the ratio increases with the inflation rate, reflecting that gains and losses under the indexing ASAP scenario become more similar to gains or losses under the full surprise scenario. Put differently, as the inflation rate increases, a short-duration asset portfolio provides relatively less inflation protection.

\section{Redistribution across Households}

Return now to the 5 percent inflation experiment. Table 2 shows that the net household positions in figure 1 and the net loss numbers in figure 5 mask large gross positions that imply considerable wealth redistribution within the household sector. As a first pass at this issue, 


\section{a}
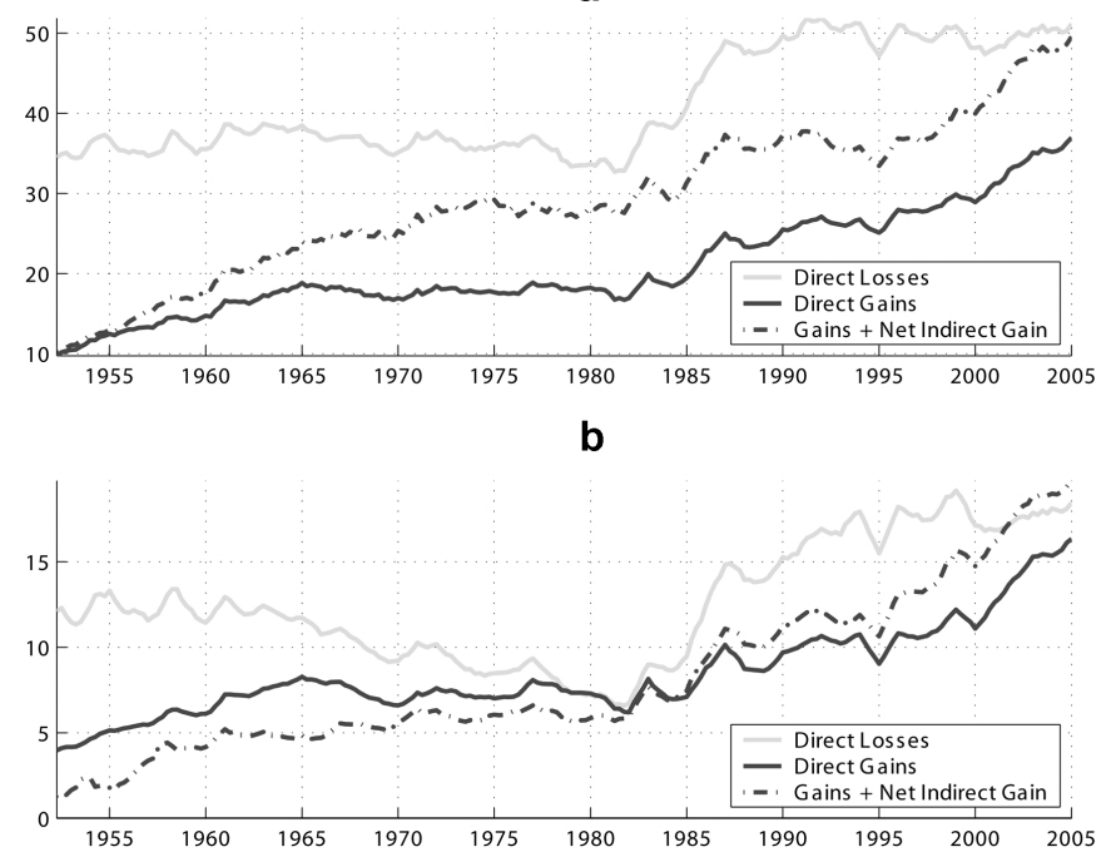

Fig. 7.-Household-sector gross gains and losses under $(a)$ full surprise and $(b)$ indexing ASAP scenarios for benchmark years 1952-2004, based on five percentage points of additional inflation per year over the next 10 years. Grey solid lines are losses on all direct nominal asset holdings. Black solid lines are gains on all direct nominal liabilities. Black dash-dot lines are gains on nominal liabilities plus debt owed indirectly through ownership of equity.

figure 7 displays changes in gross assets and liabilities of the household sector under the full surprise (fig. 7a) and indexing ASAP (fig. 7b) scenarios. Since full surprise gains and losses are a constant fraction of positions, figure $7 a$ reflects the evolution of gross assets and liabilities. It shows that gross positions are at least twice as high as net positions throughout and that the reduction in the household net position since 1980 coincides with substantial increases in both assets and liabilities, with liabilities recently rising more quickly. The scope for redistribution across households has therefore increased in recent years.

For the baseline year 1989, gains and losses for various cohorts and classes are displayed in table 3 as a percentage of mean group net worth and in table 4 as a fraction of total losses incurred by the household sector. Generally, across the two scenarios, inflation benefits the young and hurts the elderly. In terms of net worth, the gains are largest for the young middle class, a group that has substantial fixed-rate mortgage 
TABLE 3

1989 Wealth Redistribution across Households after 5 Percent Inflation Experiment Relative to Average Net Worth in Each Group

\begin{tabular}{|c|c|c|c|c|c|c|}
\hline \multirow[b]{2}{*}{ AgE COHORT } & \multicolumn{2}{|c|}{ POOR } & \multicolumn{2}{|c|}{ Middle Class } & \multicolumn{2}{|c|}{ RicH } \\
\hline & FS & IA & FS & IA & FS & IA \\
\hline$\leq 35$ & +14.4 & +.2 & +44.9 & +18.9 & +5.5 & +2.1 \\
\hline $36-45$ & +13.3 & +4.0 & +12.4 & +5.8 & -1.5 & -.9 \\
\hline $46-55$ & +2.2 & +.6 & +1.9 & +1.4 & -2.6 & -1.6 \\
\hline $56-65$ & -2.9 & -.5 & -5.5 & -1.4 & -6.4 & -2.4 \\
\hline $66-75$ & -6.9 & -1.3 & -9.9 & -2.7 & -6.6 & -2.9 \\
\hline$>75$ & -10.4 & -1.0 & -15.0 & -2.6 & -10.8 & -4.7 \\
\hline
\end{tabular}

group under two scenarios, full surprise and indexing ASAP, for baseline year 1989.

TABLE 4

1989 Wealth Redistribution across Households after a 5 Percent Inflation Experiment Relative to Total Loss of Household Sector

\begin{tabular}{|c|c|c|c|c|c|c|c|c|}
\hline \multirow[b]{2}{*}{ AgE COHORT } & \multicolumn{2}{|c|}{ ALL } & \multicolumn{2}{|c|}{ POOR } & \multicolumn{2}{|c|}{ Middle Class } & \multicolumn{2}{|c|}{ RICH } \\
\hline & FS & IA & FS & IA & FS & IA & FS & IA \\
\hline$\leq 35$ & +29.1 & +31.7 & +.5 & +.0 & +22.0 & +24.8 & +6.6 & +6.9 \\
\hline $36-45$ & +15.8 & +17.8 & +1.7 & +1.3 & +17.7 & +22.3 & -3.6 & -5.9 \\
\hline $46-55$ & -4.4 & -5.9 & +.3 & +.2 & +3.3 & +6.7 & -7.9 & -12.8 \\
\hline $56-65$ & -29.0 & -26.0 & -.3 & -.1 & -9.2 & -6.4 & -19.5 & -19.5 \\
\hline $66-75$ & -32.3 & -31.5 & -.5 & -.2 & -13.7 & -9.9 & -18.1 & -21.3 \\
\hline$>75$ & -27.2 & -23.9 & -.6 & -.2 & -10.2 & -4.7 & -16.4 & -19.0 \\
\hline All ages & -48.0 & -37.8 & +1.1 & +1.0 & +9.9 & +32.8 & -58.9 & -71.6 \\
\hline
\end{tabular}

NoTE.-Gain or loss after a 5 percent inflation episode lasting 10 years as a percentage of total loss of household sector under two scenarios, full surprise and indexing ASAP, for baseline year 1989. Losses across classes and age cohorts sum to -100 . Gains across classes and age cohorts sum to 52.1 under FS and 62.2 under IA

positions. Gains to the young poor are sizable under the full surprise scenario but smaller under indexing ASAP because the duration of the debt of the poor is shorter than that of the middle class. In terms of aggregates, middle-class households under age 45 gain between 2.6 and 5.9 percent of GDP. Gains of the young rich and poor are together less than 1.5 percent of GDP.

Who pays for these gains depends crucially on the duration of portfolios and on whether inflation is anticipated. Consider, first, losses in terms of net worth in table 3 . The rich suffer more from anticipated inflation, whereas the elderly middle class and poor are hurt more by surprise inflation. Relative to net worth, the middle-class retirees (i.e., the groups older than 65) lose most under the full surprise scenario, which hurts their saving deposits.

The rich retirees hold a smaller share of their portfolio in nominal assets, so that their full surprise loss is smaller than that of the middleclass retirees. However, to the extent that the rich do hold nominal assets, they invest more in long-term bonds. As a result, the indexing 
TABLE 5

1989 Wealth Redistribution after a 5 Percent Inflation Experiment, Mean Gain OR Loss Relative to Income

\begin{tabular}{|c|c|c|c|c|c|c|}
\hline \multirow[b]{2}{*}{ Age Cohort } & \multicolumn{2}{|c|}{$\begin{array}{c}\text { LOSERS AS A } \\
\text { PERCENTAGE } \\
\text { OF COHORT } \\
\end{array}$} & \multicolumn{2}{|c|}{ MEAN Loss } & \multicolumn{2}{|c|}{ Mean Gain } \\
\hline & FS & IA & FS & IA & FS & IA \\
\hline$\leq 35$ & .25 & .30 & -21.0 & -7.7 & +134.9 & +46.2 \\
\hline $36-45$ & .29 & .31 & -45.7 & -17.7 & +90.4 & +35.1 \\
\hline $46-55$ & .40 & .44 & -52.6 & -19.0 & +42.1 & +14.1 \\
\hline $56-65$ & .58 & .60 & -86.6 & -28.1 & +17.5 & +5.7 \\
\hline $66-75$ & .73 & .77 & -99.1 & -30.9 & +11.4 & +.7 \\
\hline$>75$ & .84 & .84 & -149.2 & -47.1 & +7.1 & +.5 \\
\hline
\end{tabular}

ASAP scenario hurts the rich retirees more (relative to net worth) than either the poor or the middle class. In terms of aggregates, old, rich households lose the most: the rich over 55 years of age account for nearly 60 percent of total household-sector losses, or between 3.1 and 8.5 percent of GDP.

To provide further perspective on magnitudes, table 5 reports the fraction of losers (i.e., net nominal borrowers) within every age cohort, together with the average (mean) gain and loss conditional on being a winner or loser. Gains and losses are stated as a percentage of average annual household income in each group. The fraction of losers and the size of the mean loss both increase with age, whereas the mean gain decreases with age under both scenarios. In the youngest cohort, close to three-quarters of households benefit from inflation, with an average gain between 46 percent and 135 percent of their average annual income. In the oldest cohort, nearly 85 percent of households lose on average about 50-150 percent of annual income.

The cohorts of middle-aged households are more heterogeneous. For example, among 46-55-year-olds, about 40 percent of households are net nominal lenders. The mean gains and losses are similar in magnitude, at about 40 percent of annual income. For this intermediate age group, the group means in table 3 (which are close to zero for all three classes) therefore understate the full scope of redistribution at the household level. However, for most younger and older cohorts, wealth changes of the smaller group (losers or winners) are relatively small.

\section{The Effect of Financial Innovation in the 1990s}

Table 6 reports cohort gains and losses as a percentage of net worth under the two scenarios for the benchmark year 2001. Here, as a general 
TABLE 6

2001 Wealth Redistribution across Households after a 5 Percent Inflation Experiment Relative to Average Net Worth in Each Group

\begin{tabular}{|c|c|c|c|c|c|c|}
\hline \multirow[b]{2}{*}{ AgE COHORT } & \multicolumn{2}{|c|}{ POOR } & \multicolumn{2}{|c|}{ Middle Class } & \multicolumn{2}{|c|}{ Rich } \\
\hline & FS & IA & FS & IA & FS & IA \\
\hline$\leq 35$ & +54.4 & +19.9 & +55.5 & +30.9 & +2.8 & +2.5 \\
\hline $36-45$ & +21.3 & +11.5 & +16.2 & +11.4 & +1.4 & +1.2 \\
\hline $46-55$ & +12.3 & +4.8 & +3.7 & +2.9 & -.8 & -.4 \\
\hline $56-65$ & -.1 & -.4 & -2.2 & -1.3 & -4.2 & -2.2 \\
\hline $66-75$ & -.3 & +.1 & -5.6 & -1.7 & -4.6 & -2.2 \\
\hline$>75$ & -7.5 & -.4 & -9.4 & -2.2 & -5.4 & -2.5 \\
\hline
\end{tabular}

NotE.-Gain or loss after a 5 percent inflation episode lasting 10 years as a percentage of average net worth in each group under two scenarios, full surprise and indexing ASAP, for baseline year 2001.

rule, compared to the 1989 numbers, the elderly have smaller losses, whereas the young have somewhat larger gains. In other words, the reduction in total household-sector losses between 1989 and 2001 that we saw in table 2 is present also at the more disaggregated group level. Another feature common to both tables is that losses are more similar for the two benchmark years under the indexing ASAP scenario than under the full surprise scenario. This reflects the portfolio shift toward longer-term nominal positions discussed earlier. While U.S. nominal savers have become less exposed to surprise inflation, they have not become much less vulnerable to anticipated inflation.

We illustrate various forces that drove down the positive NNP of older households by focusing on the middle-class cohort aged 56-65. Between 1989 and 2001, the loss of this group as a percentage of net worth fell by more than half-from 5.5 percent to 2.2 percent-under the full surprise scenario and by less than 10 percent-from 1.4 to 1.3 percentunder indexing ASAP. In the full surprise scenario, a major part of the reduction was due to smaller losses on short positions, from 4.3 to 2.9 percent. However, this group's loss on long bond positions actually increased, from 5.3 to 7.5 percent. Another factor behind the group's smaller loss is the gain on indirect debt due to equity holdings, which increased from 0.9 to 2.2 percent. Finally, the group's gain on mortgage debt increased from 3.4 to 6.0 percent. Under the indexing ASAP scenario, their losses on short positions were negligible. The larger gains on mortgages and equity were then nearly balanced by the larger losses on bonds; the overall losses in 1989 and 2001 are thus almost the same. ${ }^{9}$

Decompositions of the change in losses for other old net lender house-

\footnotetext{
${ }^{9}$ The gain from indirect debt is large not only because the rich held more equity in 2001 but also because the maturity mismatch in the corporate sector had been reduced since 1989. Indeed, the gain on indirect debt under indexing ASAP was 0.1 percent in 1989 , less than one-tenth of the full surprise gain, but 0.8 percent in 2001, more than one-third of the full surprise gain.
} 
hold groups yield qualitatively similar results. The portfolio shift from short to long nominal assets, the increasing importance of indirect debt, and the repayment of mortgages later in life are the key developments that changed the losses of net lenders. Among the changes in the gains to net borrowers, the most striking is how similar the poor have become to the middle class. While the poor between the ages of 35 and 55 were already gaining significantly under the full surprise scenario in 1989 , their 2001 gains mimic those of the middle class for all households under age 55 under both scenarios. The poor have adapted to borrow not only as early in life as the middle class but also at similarly long durations, via mortgage loans.

\section{Conclusion}

Our goal here was to quantitatively assess the wealth redistributional effects of inflation in the United States. We have documented the distribution and duration of nominal assets and liabilities in the postwar U.S. economy, and we have used those numbers to compute the wealth redistribution that would be induced by a moderate inflation episode, similar in magnitude to what the United States experienced in the 1970s. Our main result is that even moderate inflation leads to a sizable redistribution of wealth. Within the household sector, the main losers from inflation are rich, old households, whereas the main winners are young, middle-class households with mortgage debt. Across sectors, inflation is a boon for the government and a tax on foreigners. Lately, the net nominal position of the rest of the world has grown dramatically, increasing the potential for a large inflation-induced wealth transfer from foreigners to domestic households. We also find that the redistributional effects induced by surprising realized inflation differ from those induced by surprising news about future inflation. While knowing the size of nominal positions is sufficient to calculate the former, duration is needed to gauge the latter.

Our analysis raises questions for future research. One major issue is how macroeconomic aggregates respond to a redistribution shock caused by an inflation episode. Do the responses of individual households cancel out, or do aggregate consumption, savings, and labor supply react? Some of these questions are addressed in Doepke and Schneider (2006a), where we show how asymmetries in the economic characteristics of winners and losers can bring about aggregate effects of an inflation episode. Our results also suggest that fiscal policy can play a central role in shaping the effects of an inflation episode. Indeed, in all our experiments the government is a major winner, which implies that fiscal policy has to adjust in some dimension to satisfy the government budget constraint. Fiscal policy changes could offset or reinforce 
the redistributional effects we have identified here. In Doepke and Schneider $(2006 b)$ we describe one specific set of fiscal responses and study their effects on macroeconomic aggregates and welfare.

\section{References}

Albanesi, Stefania. Forthcoming. "Inflation and Inequality." J. Monetary Econ.

Antoniewicz, Rochelle L. 2000. "A Comparison of the Household Sector from the Flow of Funds Accounts and the Survey of Consumer Finances." Manuscript, Fed. Reserve Bd., Washington, DC.

Bach, G. L., and James B. Stephenson. 1974. "Inflation and the Redistribution of Wealth.” Rev. Econ. and Statis. 56 (February): 1-13.

Barclay, Michael J., and Clifford W. Smith Jr. 1999. "On Financial Architecture: Leverage, Maturity, and Priority." In The New Corporate Finance, edited by Donald H. Chew. Boston: McGraw-Hill.

Bohn, Henning. 1988. "Why Do We Have Nominal Government Debt?" J. Monetary Econ. 21 (January): 127-40.

- 1990a. "A Positive Theory of Foreign Currency Debt." J. Internat. Econ. 29 (November): 273-92.

1990b. "Tax Smoothing with Financial Instruments." A.E.R. 80 (December): 1217-30.

Burnside, Craig, Martin Eichenbaum, and Sergio Rebelo. 2006. "Government Finance in the Wake of Currency Crises." J. Monetary Econ. 53 (April): 40140.

Cukierman, A., K. Lennan, and F. Papadia. 1985. "Inflation-Induced Redistributions via Monetary Assets in Five European Countries: 1974-1982.” In Economic Policy and National Accounting in Inflationary Conditions, Studies in Banking and Finance, vol. 2, edited by Jørgen Mortensen. Amsterdam: NorthHolland.

Doepke, Matthias, and Martin Schneider. 2006a. "Aggregate Implications of Wealth Redistribution: The Case of Inflation.” J. European Econ. Assoc. 4 (April/ May): 493-502.

. 2006b. "Inflation as a Redistribution Shock: Effects on Aggregates and Welfare.” Working Paper no. 12319 (June), NBER, Cambridge, MA.

Erosa, Andrés, and Gustavo Ventura. 2002. "On Inflation as a Regressive Consumption Tax.” J. Monetary Econ. 49 (May): 761-95.

Gourinchas, Pierre-Olivier, and Hélène Rey. 2005. "International Financial Adjustment." Working Paper no. 11155 (February), NBER, Cambridge, MA.

Hall, Robert E. 2001. "The Stock Market and Capital Accumulation." A.E.R. 91 (December): 1185-1202.

McCulloch, J. Huston. 1990. "The Term Structure of Interest Rates: Appendix B: U.S. Term Structure Data, 1946-87." In Handbook of Monetary Economics, vol. 1, edited by Benjamin M. Friedman and Frank H. Hahn. Amsterdam: Elsevier.

McGrattan, Ellen R., and Edward C. Prescott. 2005. "Taxes, Regulations, and the Value of U.S. and U.K. Corporations.” Rev. Econ. Studies 72 (July): 76796.

Persson, Mats, Torsten Persson, and Lars E. O. Svensson. 1998. "Debt, Cash Flow and Inflation Incentives: A Swedish Example." In The Debt Burden and Its Consequences for Monetary Policy, edited by Guillermo Calvo and Mervyn King. New York: St. Martin's (for Internat. Econ. Assoc.). 
Sims, Christopher A. 2001. "Fiscal Consequences for Mexico of Adopting the Dollar." J. Money, Credit, and Banking 33, no. 2, pt. 2 (May): 597-616.

Stigum, Marcia. 1990. The Money Market. 3rd ed. Homewood, IL: Dow JonesIrwin. 